Am J Prev Med. 2019 May ; 56(5): 639-647. doi:10.1016/j.amepre.2018.12.009.

\title{
U.S. Emergency Department Visits Resulting From Nonmedical Use of Pharmaceuticals, 2016
}

\author{
Andrew I. Geller, MD ${ }^{1}$, Deborah Dowell, MD, MPH ${ }^{2}$, Maribeth C. Lovegrove, MPH $^{1}$, Jana K. \\ McAninch, MD, MPH, MS ${ }^{3}$, Sandra K. Goring, RN, BSN ${ }^{1}$, Kathleen O. Rose, RN, BSN ${ }^{1}$, Nina \\ J. Weidle, PharmD ${ }^{1}$, and Daniel S. Budnitz, MD, MPH ${ }^{1}$
}

${ }^{1}$ Division of Healthcare Quality Promotion, Centers for Disease Control and Prevention (CDC), Atlanta, Georgia ${ }^{2}$ National Center for Injury Prevention and Control, CDC, Atlanta, Georgia ${ }^{3}$ Center for Drug Evaluation and Research, Food and Drug Administration, Silver Spring, Maryland

\section{Abstract}

Introduction: National data on morbidity from nonmedical use of pharmaceuticals are limited. This study used nationally representative, public health surveillance data to characterize U.S. emergency department visits for acute harms from nonmedical use of pharmaceuticals and to guide prevention efforts.

Methods: Data collected in 2016 from the National Electronic Injury Surveillance SystemCooperative Adverse Drug Event Surveillance project were analyzed in 2018 to calculate national estimates of emergency department visits for harms from nonmedical use of pharmaceuticals.

Results: From review of 5,130 cases, there were an estimated 358,247 emergency department visits $(95 \% \mathrm{CI}=280,675,435,819)$ in 2016 for harms from nonmedical use of pharmaceuticals and $41.1 \%$ resulted in hospitalization $(95 \% \mathrm{CI}=32.3 \%, 49.8 \%)$. One half $(50.9 \%, 95 \% \mathrm{CI}=46.6 \%$, $55.3 \%$ ) of estimated visits involved patients aged $\$ 34$ years; more than one half of estimated visits also involved non-pharmaceutical substances $(52.9 \%, 95 \% \mathrm{CI}=49.7 \%, 56.1 \%)$, including illicit drugs in $34.1 \%$ (95\% CI $=30.9 \%, 37.2 \%)$ and alcohol in $21.8 \%$ (95\% CI=19.8\%, 23.9\%). Overall, benzodiazepines were implicated in $46.9 \%$ (95\% CI=42.5\%, $51.2 \%$ ) of estimated emergency department visits for nonmedical use of pharmaceuticals but were the only substance implicated in just $6.5 \%$ (95\% CI=5.1\%, 7.9\%). Prescription opioids were implicated in $36.2 \%$ (95\% CI=30.8\%, $41.7 \%$ ) of estimated emergency department visits and were the only substance implicated in $11.3 \%(95 \% \mathrm{CI}=8.6 \%, 14.0 \%)$.

Conclusions: Although prescription opioids or benzodiazepines are frequently implicated in emergency department visits for nonmedical use, because other substances and additional

Address correspondence to: Daniel S. Budnitz MD, MPH, Division of Healthcare Quality Promotion, CDC, Mailstop V18-4, 1600 Clifton Road, NE, Atlanta GA 30333.dbudnitz@cdc.gov.

Author contributions were as follows: Geller and Budnitz helped with study conception and design and drafting of the manuscript; all authors helped with acquisition of data, analysis and interpretation of data, critical revision for important intellectual content, and administrative, technical, or logistical support; Geller performed statistical analysis; and Budnitz supervised the study. 
pharmaceuticals are most often involved, prescribing clinicians should consider implementing specific screening to address polysubstance use and, when warranted, treatment interventions.

\section{INTRODUCTION}

Nonmedical use of pharmaceuticals includes a spectrum of circumstances of use, from using a medication to manage a condition, but in a frequency, dose, or other manner that is not recommended, to using the medication to attain euphoria or other psychological or physiologic effect without medical justification. ${ }^{1,2}$

Nonmedical use of pharmaceuticals gained renewed attention in the last decade. The increase in deaths from prescription opioids has been called an epidemic ${ }^{3}$ and overdoses from opioids (prescription and illicit) led HHS to declare a public health emergency in 2017..$^{4}$ Additionally, concerns have arisen about nonmedical use of pharmaceuticals other than opioids, such as benzodiazepines, non-benzodiazepine sleeping aids, stimulants, cough and cold products, and gabapentinoids. ${ }^{5-10}$ To target interventions prior to fatal outcomes, data on morbidity from nonmedical use of pharmaceuticals can be helpful; however, since discontinuation of the Drug Abuse Warning Network after 2011, detailed national data describing morbidity from nonmedical use of pharmaceuticals are limited. ${ }^{11}$ A newly expanded, nationally representative public health surveillance system is used to estimate numbers of emergency department (ED) visits for pharmaceutical harms by patient characteristics and intent of use, and identify clinical manifestations and specific implicated products.

\section{METHODS}

\section{Study Sample}

National estimates of ED visits for harms from pharmaceuticals were based on data from the National Electronic Injury Surveillance System-Cooperative Adverse Drug Event Surveillance (NEISS-CADES) project, a joint collaboration of the Centers for Disease Control and Prevention (CDC), the U.S. Consumer Product Safety Commission, and Food and Drug Administration. NEISS-CADES is an active public health surveillance system based on a nationally representative, stratified probability sample of 56 U.S hospitals with at $\succeq 6$ beds and a 24 -hour ED. ${ }^{12-14}$

Trained data abstractors review clinical records of every ED visit to identify harms (adverse events) from therapeutic pharmaceutical use and, beginning in 2016, harms caused by pharmaceuticals used for any intent. Abstractors record up to four implicated pharmaceuticals, patient demographics, intent of pharmaceutical use, narrative descriptions of the event (including clinical manifestations, precipitating circumstances, and use of illicit drugs or alcohol in addition to pharmaceuticals), clinician diagnoses, laboratory testing, treatments administered, and discharge disposition. Clinical manifestations are coded by CDC using the Medical Dictionary for Regulatory Activities, version 9.1. Data collection from the NEISS-CADES project hospitals has been deemed a public health surveillance activity by the CDC human subject oversight bodies and did not require IRB approval. ${ }^{15}$ 


\section{Measures}

For this analysis (performed in 2018), cases included ED visits for pharmaceutical harms from January 1, 2016 to December 31, 2016. In some cases, pharmaceuticals were identified from toxicology testing (e.g., when patients were unable or unwilling to provide a drug use history). Cases involving unspecified drugs (e.g., diagnosis of opioid overdose but no indication if the opioid was a pharmaceutical product or heroin) were excluded. Cases involving inadequate therapy, drug withdrawal, detoxification treatment, medical clearance, occupational exposures, harms from ED treatment, and deaths are not included. Cases involving self-harm (administration of pharmaceuticals to injure or kill oneself) or unsupervised pediatric ingestions were excluded.

Intent of pharmaceutical use was classified as therapeutic (e.g., adverse effects, allergic reactions, medication errors) or nonmedical use. Nonmedical use includes abuse, therapeutic misuse, and overdoses without indication of intent. Abuse cases involve documented clinician diagnosis of abuse or documented recreational use (e.g., "to get high"); although concern has been raised that the term "abuse" may contribute to stigma, ${ }^{16,17}$ it is employed here because the term remains commonly used by clinicians in their medical documentation. Therapeutic misuse cases involved documented therapeutic intent, but use was not as directed (e.g., taking someone else's prescription medication for pain, intentionally taking larger doses than prescribed). Cases of overdoses without indication of intent lacked documentation of therapeutic intent, abuse, or self-harm (e.g., patients found unresponsive by paramedics and patients unable or unwilling to provide description of circumstances or intent).

\section{Statistical Analysis}

Each reported case is assigned a weight based on the inverse probability of selection, with adjustment for nonresponse, and post-stratified to adjust for changes in the total number of annual hospital ED visits. ${ }^{13,14}$ National estimates of ED visits were calculated using these weights and corresponding 95\% CIs were calculated to account for the sample design by using the SAS SURVEYMEANS procedure. Estimates based on $<20$ cases or total estimates $<1,200$ are considered statistically unstable and are not shown. Estimates with coefficient of variation $>30 \%$ may be statistically unstable and are noted.

\section{RESULTS \\ Case Characteristics}

Based on 5,130 surveillance cases from 56 EDs, there were an estimated 358,247 (95\% $\mathrm{CI}=280,675,435,819) \mathrm{ED}$ visits for harms from nonmedical use of pharmaceuticals in 2016 (hereafter nonmedical use visits), compared with 1,474,556 (95\% CI=980,473, 1,968,639) ED visits for harms from therapeutic use of pharmaceuticals. More than four fifths (83.4\%, $95 \% \mathrm{CI}=80.9 \%, 85.8 \%)$ of nonmedical use visits involved abuse $(39.7 \%)$ or overdoses without indication of therapeutic intent, abuse, or self-harm (43.7\%); misuse for a therapeutic purpose was documented in $16.6 \%$ of estimated visits. 
One half $(50.9 \%, 95 \% \mathrm{CI}=46.6 \%, 55.3 \%)$ of estimated nonmedical use visits involved patients aged $\$ 34$ years (Table 1). Among patients aged 15-34 years, the estimated number of nonmedical use visits $(175,107,95 \% \mathrm{CI}=133,910,216,305)$ approached the number of visits involving therapeutic use $(240,757,95 \% \mathrm{CI}=171,238,310,277)$. Among patients aged $\checkmark 65$ years, the estimated number of nonmedical use visits $(17,303,95 \% \mathrm{CI}=11,303,23,303)$ was 30 -fold less than the number of visits involving therapeutic use $(589,431,95 \%$ $\mathrm{CI}=329,195,849,668)$.

Patient demographics and disposition from the ED were similar for visits for abuse and for overdoses without indication of intent; patient demographics and disposition from the ED were similar for visits for therapeutic misuse and therapeutic use (Appendix Table 1). Overall, most (55.7\%) estimated nonmedical use visits were made by males (Table 1); however, females made most of the nonmedical use visits involving therapeutic misuse $(54.5 \%, 95 \% \mathrm{CI}=50.7 \%, 58.2 \%)$, similar to the proportion of visits by females involving therapeutic use $(55.7 \%)$.

Overall, an estimated $41.1 \%$ of nonmedical use visits resulted in hospitalization. Hospitalization was more common for nonmedical use visits involving abuse $(36.3 \%, 95 \%$ $\mathrm{CI}=25.5 \%, 47.1 \%)$ or overdoses without indication of intent $(50.5 \%, 95 \% \mathrm{CI}=41.4 \%$, $59.7 \%)$ than for therapeutic misuse visits $(27.5 \%, 95 \% \mathrm{CI}=21.4 \%, 33.7 \%)$, which resulted in hospitalization as frequently as visits for therapeutic use (27.2\%).

Although a single pharmaceutical was implicated in $72.1 \%$ of estimated nonmedical use visits, most visits (52.9\%) involved use of at least one non-pharmaceutical substance, most commonly alcohol (21.8\%), marijuana (17.7\%), and cocaine (10.5\%). At least one illicit substance was documented in $44.1 \%(95 \% \mathrm{CI}=40.5 \%, 47.8 \%)$ of estimated nonmedical use visits involving abuse compared with $9.4 \%(95 \% \mathrm{CI}=7.0 \%, 11.7 \%)$ of nonmedical use ED visits involving therapeutic misuse. Use of illicit substances was rarely documented in ED visits involving therapeutic use of pharmaceuticals $(0.6 \%)$.

\section{Type of Pharmaceutical Involved}

Overall, benzodiazepines and opioids were the most common pharmaceutical classes involved in ED visits for nonmedical use. Benzodiazepines were involved in 167,845 (46.9\%) of estimated nonmedical use visits and prescription opioids were involved in $129,863(36.2 \%)$ of nonmedical use visits (Table 2). Benzodiazepines or prescription opioids were involved in $71.0 \%$ (95\% CI=67.2\%, 74.8\%) of nonmedical use ED visits.

Benzodiazepines and prescription opioids were co-implicated in $12.1 \%$ (95\% CI $=9.4 \%$, $14.8 \%$ ) of nonmedical use visits. No other pharmaceutical category was involved in $>10 \%$ of nonmedical use visits.

Although benzodiazepines were involved in more ED visits for nonmedical use than any other drug class, in $26.4 \%$ of estimated nonmedical use visits involving benzodiazepines (95\% CI $19.7 \%, 33.1 \%$ ), the benzodiazepine was identified from laboratory test results only; in $7.4 \%$ of visits involving opioids, the opioid was identified by laboratory testing only $(95 \% \mathrm{CI}=4.1 \%, 10.7 \%)$. In addition, benzodiazepines were implicated alone (without 
involvement of other pharmaceutical or non-pharmaceutical substances) in far fewer estimated nonmedical use visits $(23,335,6.5 \%)$ than opioids alone $(40,550,11.3 \%$; Table 2$)$.

Therapeutic misuse was the most common type of nonmedical use for ED visits involving antibiotics $(76.5 \%, 95 \% \mathrm{CI}=63.4 \%, 89.7 \%)$ and nonopioid analgesics $(48.1 \%, 95 \%$ $\mathrm{CI}=41.6 \%, 54.5 \%)$. One third of nonmedical use visits involving antihypertensives $(36.7 \%$, $95 \% \mathrm{CI}=21.7 \%, 51.6 \%)$ and one quarter of visits involving muscle relaxants $(28.5 \%, 95 \%$ $\mathrm{CI}=17.9 \%, 39.0 \%$ ) were attributed to therapeutic misuse.

\section{Patient Characteristics and Type of Pharmaceutical Involved}

Males made most of the estimated nonmedical use visits involving stimulants (61.0\%, $95 \%$ $\mathrm{CI}=50.9 \%, 71.0 \%)$, cough/cold products or antihistamines $(59.8 \%, 95 \% \mathrm{CI}=53.2 \%, 66.4 \%)$, prescription opioids $(57.6 \%, 95 \% \mathrm{CI}=54.8 \%, 60.4 \%)$, or benzodiazepines $(57.2 \%, 95 \%$ $\mathrm{CI}=54.7 \%, 59.7 \%$; Appendix Figure 1).

Patients aged $<35$ years made almost three quarters of estimated visits involving cough/cold or antihistamine-containing products $(71.3 \%, 95 \% \mathrm{CI}=65.2 \%, 77.4 \%)$ and stimulants (71.4\%, 95\% CI=61.9\%, 81.0\%); and approximately one half of estimated visits involving nonopioid analgesics $(56.4 \%, 95 \% \mathrm{CI}=49.6 \%, 63.1 \%)$, benzodiazepines $(53.1 \%, 95 \%$ $\mathrm{CI}=50.6 \%, 55.7 \%)$, anticonvulsants $(47.7 \%, 95 \% \mathrm{CI}=32.8 \%, 62.6 \%)$, antidepressants $(47.1 \%, 95 \% \mathrm{CI}=40.4 \%, 53.9 \%)$, and antipsychotics $(44.9 \%, 95 \% \mathrm{CI}=37.1 \%, 52.7 \%$;

Appendix Figure 2). Adults aged $\succeq 65$ years made too few nonmedical use visits to calculate stable estimates of ED visits for categories other than benzodiazepines $(4.1 \%, 95 \%$ $\mathrm{CI}=3.0 \%, 5.1 \%)$ and prescription opioids $(6.2 \%, 95 \% \mathrm{CI}=4.8 \%, 7.6 \%)$.

\section{Involvement of Other Substances}

Multiple pharmaceuticals or other substances were documented to be involved in at least two thirds of estimated nonmedical use visits involving gabapentinoids $(88.8 \%, 95 \% \mathrm{CI}=82.6 \%$, $95.1 \%)$, benzodiazepines $(86.1 \%, 95 \% \mathrm{CI}=83.1 \%, 89.1 \%)$, non-benzodiazepine hypnotics $(85.9 \%, 95 \% \mathrm{CI}=79.7 \%, 92.2 \%)$, muscle relaxants $(78.9 \%, 95 \% \mathrm{CI}=71.1 \%, 86.6 \%)$, antidepressants $(75.3 \%, 95 \% \mathrm{CI}=69.3 \%, 81.3 \%)$, prescription opioids $(68.8 \%, 95 \%$ $\mathrm{CI}=63.9 \%, 73.8 \%)$, and antipsychotics $(68.5 \%, 95 \% \mathrm{CI}=62.7 \%, 74.4 \%$; Figure 1). Use of illicit drugs or alcohol was documented in an estimated $62.0 \%$ of nonmedical use visits involving benzodiazepines ( $95 \% \mathrm{CI}=59.0 \%, 64.9 \%$ ), but in less than one half of nonmedical use visits involving other categories: stimulants $(46.5 \%, 95 \% \mathrm{CI}=35.4 \%, 57.6 \%)$, nonbenzodiazepine hypnotics $(45.2 \%, 95 \% \mathrm{CI}=37.3 \%, 53.1 \%)$, prescription opioids ( $43.8 \%$, $95 \% \mathrm{CI}=41.2 \%, 46.3 \%)$, antidepressants $(42.3 \%, 95 \% \mathrm{CI}=36.8 \%, 47.8 \%)$, and gabapentinoids $(37.9 \%, 95 \% \mathrm{CI}=26.6 \%, 49.3 \%)$. Concurrent use of illicit drugs was most commonly documented for nonmedical use visits involving benzodiazepines and prescription opioids, accounting for an estimated $44.5 \%$ and $33.1 \%$ of nonmedical use visits, respectively $(95 \% \mathrm{CI}=40.5 \%, 48.6 \%$, and $95 \% \mathrm{CI}=30.5 \%, 35.7 \%)$.

\section{Clinical Manifestations}

Nonmedical use visits frequently involved severe overdose. Overall, patients were unresponsive or experienced cardiorespiratory failure in $22.6 \%$ of estimated nonmedical use 
visits and patients had altered mental status in an additional 35.4\% of visits (Table 3). Unresponsiveness or cardiorespiratory failure was documented in more than one quarter of nonmedical use visits involving either a benzodiazepine $(27.2 \%, 95 \% \mathrm{CI}=19.6 \%, 34.7 \%)$ or a prescription opioid $(29.6 \%, 95 \% \mathrm{CI}=22.3 \%, 36.9 \%)$, but only one tenth $(9.6 \%, 95 \%$ $\mathrm{CI}=6.6 \%, 12.6 \%$ ) of nonmedical use visits not involving neither a benzodiazepine nor a prescription opioid. Excluding cases of co-implication with prescription opioids, unresponsiveness or cardiorespiratory failure was documented in $38.0 \%$ (95\% CI=28.4\%, $47.5 \%$ ) of benzodiazepine nonmedical use visits involving an illicit drug (other than marijuana alone), compared with $18.5 \%$ (95\% CI=8.5\%, 28.5\%) of visits involving no other substance. For visits involving co-implication of benzodiazepines and prescription opioids, unresponsiveness or cardiorespiratory failure was present in $28.9 \%$ (95\% CI=19.5\%, 38.2\%) of the visits involving an illicit drug (other than marijuana alone), compared with $29.2 \%$ $(95 \% \mathrm{CI}=22.2 \%, 36.3 \%)$ of visits involving prescription opioids alone.

\section{DISCUSSION}

Harm from nonmedical use of pharmaceuticals led to an estimated 358,247 ED visits in the U.S. in 2016, with 23\% involving unresponsiveness or cardiorespiratory failure and $40 \%$ resulting in hospitalization.

Despite indications of declining medical opioid prescribing, ${ }^{18}$ nonmedical opioid use remains prevalent, ${ }^{19}$ and ED visit morbidity data highlight opportunities for targeted prevention before patients suffer fatal overdoses from opioids. Two fifths of ED visits by patients treated for nonmedical use of opioids involved patients younger than 35 years, and $29 \%$ of patients treated for nonmedical use of opioids experienced unresponsiveness or cardiorespiratory failure. Although patients treated for nonfatal overdose have increased risk of another overdose, ${ }^{20-22}$ and naloxone, which has shown efficacy in tertiary prevention of fatal opioid overdoses, naloxone is not routinely made available to overdose patients at ED discharge. ${ }^{23}$ Thus, efforts to expand naloxone distribution could initially target patients who receive emergency care for serious overdose symptoms and their families and friends. ${ }^{24,25} \mathrm{In}$ addition, the ED can be a place to initiate secondary preventive interventions, such as brief motivational interviewing, ${ }^{26,27}$ connecting patients to peer navigators for follow-up, and linking to or initiating medication-assisted treatment. ${ }^{11,28-30}$ As $68.8 \%$ of the estimated 130,000 ED visits resulting from nonmedical use of opioids involved other pharmaceuticals, alcohol, or illicit substances, primary prevention efforts (in the ED or outpatient office) to reduce ED visits resulting from nonmedical use of opioids include screening for substance use before prescribing opioids, prescribing the lowest effective dose, and avoiding coprescription with benzodiazepines when possible. ${ }^{25,31,32}$

Although the number of nonmedical use visits involving benzodiazepines was estimated to be higher than the number involving opioids in 2016, the degree to which benzodiazepines contributed to harms is less certain. First, in $26 \%$ of visits for nonmedical use involving benzodiazepines, the presence of benzodiazepines was based on laboratory findings in visits with a general diagnosis, such as drug overdose. Second, benzodiazepines were rarely the sole substance implicated in ED visits for nonmedical use. Use of benzodiazepines alone only accounted for one seventh of benzodiazepine nonmedical use visits. By comparison, 
opioids alone accounted for one third of opioid nonmedical use visits. Third, additional substances appear to play a more prominent role in harms from nonmedical benzodiazepine use. Unlike opioid visits, benzodiazepine visits involved more severe effects (unresponsiveness or cardiorespiratory failure) when illicit substance use was also documented.

Should similar interventions be considered for benzodiazepines as for opioids? The benzodiazepine reversal agent flumazenil does not currently exist in auto-injector form, but even if it were developed, the frequency of co-implication with opioids (prescription and illicit) reduces the likelihood of benefit in these patients. Instead, screening to identify opioid use and recent opioid overdose history in patients prescribed benzodiazepines should prompt consideration of naloxone prescription. Screening patients prescribed benzodiazepines for use of other pharmaceuticals, alcohol, and illicit substances and addressing the use of these other substances may impact an even higher proportion of patients compared with screening those prescribed opioids, as a higher proportion of both ED visits and deaths involving benzodiazepines also involve such other substances. Although there currently is no Food and Drug Administration-approved medication to assist treatment for benzodiazepine dependence, behavioral interventions such as motivational interviewing could also apply to patients treated in EDs following nonmedical use of benzodiazepines. ${ }^{33}$ Adoption of similar primary prevention approaches to those for opioids is warranted, such as judicious prescribing, and avoidance where possible of co-prescription of benzodiazepines with opioids. ${ }^{25,34}$

Reports of increased use of non-opioid pharmaceuticals (e.g., gabapentinoids, ${ }^{35-37}$ loperamide, ${ }^{38,39}$ and stimulants ${ }^{40}$ ) have prompted concerns for missing the next drug epidemic, but neither large numbers nor high severity of ED visits attributed to other pharmaceuticals were identified. Only $29 \%$ of estimated ED visits for nonmedical use did not involve opioids or benzodiazepines, and these visits were less likely than visits involving opioids or benzodiazepines to involve severe manifestations of unresponsiveness or cardiorespiratory failure (9.6\%). Gabapentinoids, approved for seizure control and selected pain syndromes but increasingly prescribed for other pain indications, were involved in 3.3\% of nonmedical use ED visits but most often involved other substances as well (88.8\%). Thus, similar to benzodiazepines, the contribution of gabapentinoids to severe outcomes is not clear; yet, screening for other medication and substance use may also be appropriate for patients prescribed gabapentinoids. There were not enough ED visits involving nonmedical use of loperamide or kratom to calculate national estimates, although harms from these drugs may be less well-recognized in the ED setting. Most non-opioid, non-benzodiazepine nonmedical use visits involved pharmaceuticals known to be misused predominantly by certain age groups. Seven of ten ED visits for nonmedical use of cough/cold or antihistamine products and prescription stimulants involved patients aged younger than 35 years; six of ten ED visits for nonmedical use of muscle relaxants, gabapentinoids, and non-benzodiazepine hypnotics involved patients aged 35 years or older. 


\section{Limitations}

Public health surveillance data used for this report have limitations. First, the overall burden of morbidity from nonmedical use of pharmaceuticals is underestimated, as only acute harms that are treated in EDs are included, with a maximum of four implicated products. Chronic conditions secondary to nonmedical use of pharmaceuticals that are not typically identified as such in EDs, such as certain infectious complications (e.g., HIV, hepatitis C virus), are not represented. Patients treated in other healthcare settings or non-healthcare settings (e.g., bystander naloxone administration), patients whose harms are not acute effects of active pharmaceutical use (e.g., withdrawal, seeking detoxification and substance use disorder treatment, and violence-related injuries), patients for whom a drug history could not be obtained, and deaths in or en route to the ED were not included. Second, because ED documentation is focused on recording the information deemed most relevant to clinical decision making, data helpful for public health surveillance may be incomplete. For example, 646 cases (representing nearly 46,000 estimated nonmedical use visits) were excluded because an unspecified drug (e.g., "opioid," "amphetamine") was the only product documented, as those cases could have involved prescription or illicit products (e.g., heroin, illicit methamphetamine). On the other hand, nonmedical use may be overestimated by including visits in which intent could not be determined (e.g., unresponsive patients) as some of these visits could have involved therapeutic use or self-harm attempts. ${ }^{41-43}$ Third, some implicated pharmaceuticals and concomitant illicit drugs were identified based on laboratory testing alone, which could bias towards identification of drugs included on standard ED toxicology screens (e.g., benzodiazepine, methadone) and potentially against others (e.g., gabapentinoids). Similarly, there is the potential for cross-reactivity for laboratory tests, and some identified drugs may represent false positives. Finally, with a sample of less than 60 hospitals, state-level estimates are not possible and localized variations may not be reflected.

\section{CONCLUSIONS}

Nonmedical use of pharmaceuticals is a common cause of ED visits in the U.S. for medication-related harm, particularly among young adults, and represents an important opportunity for prevention. Although opioids and benzodiazepines account for most nonmedical use visits, additional substances (licit and illicit) are often involved. Thus, prescribing physicians should consider implementing specific screening to address polysubstance use and, when warranted, treatment interventions. Even though other pharmaceuticals are involved in far fewer ED visits for nonmedical use than opioids and benzodiazepines, ongoing surveillance remains important to identify emerging trends.

\section{Supplementary Material}

Refer to Web version on PubMed Central for supplementary material.

\section{ACKNOWLEDGMENTS}

The authors thank Ms. Arati Baral and Mr. Alex Tocitu, from Northrop Grumman (contractor to Centers for Disease Control and Prevention [CDC]), for assistance with data coding and programming. The authors also thank Mr. Tom Schroeder, Ms. Elenore Sonski, Mr. Herman Burney, and data abstractors from the U.S. Consumer Product Safety 
Commission, for their assistance with data acquisition. No individuals named herein received compensation for their contributions.

The findings in and conclusions of this study are those of the authors and do not necessarily represent the official position of CDC or Food and Drug Administration.

Funded solely by HHS, which had no role in study design; collection, analysis, and interpretation of data; writing the report; and decision to submit the report for publication.

No financial disclosures were reported by the authors of this paper.

\section{REFERENCES}

1. HHS, NIH, National Institute on Drug Abuse. Research Report: Misuse of Prescription Drugs www.drugabuse.gov/publications/research-reports/misuse-prescription-drugs/summary. Updated January 2018. Accessed June 3, 2018.

2. HHS, Food and Drug Administration, Center for Drug Evaluation and Research. Assessment of abuse potential of drugs - guidance for industry www.fda.gov/downloads/drugs/ guidancecomplianceregulatoryinformation/guidances/ucm198650.pdf. Updated January 2018. Accessed June 4, 2018.

3. Paulozzi LJ, Budnitz DS, Xi Y. Increasing deaths from opioid analgesics in the United States. Pharmacoepidemiol Drug Saf 2006;15(9):618-627. 10.1002/pds.1276. [PubMed: 16862602]

4. HHS. HHS Acting Secretary Declares Public Health Emergency to Address National Opioid Crisis [press release] www.hhs.gov/about/news/2017/10/26/hhs-acting-secretary-declares-public-healthemergency-address-national-opioid-crisis.html. Published 2017 Updated April 24, 2018. Accessed December 16, 2018.

5. HHS, CDC, National Center for Health Statistics. Multiple Cause of Death 1999-2016 on CDC WONDER Online Database http://wonder.cdc.gov/mcd-icd10.html. Updated December 2017. Accessed March 30, 2018.

6. HHS, NIH, National Institute on Drug Abuse. Opioid involvement in benzodiazepine overdose www.drugabuse.gov/related-topics/trends-statistics/overdose-death-rates. Updated September 2017. Accessed March 30, 2018.

7. Lembke A, Papac J, Humphreys K. Our other prescription drug problem. N Engl J Med 2018;378(8):693-695. 10.1056/NEJMp1715050. [PubMed: 29466163]

8. Ladapo JA, Larochelle MR, Chen A, et al. Physician prescribing of opioids to patients at increased risk of overdose from benzodiazepine use in the United States. JAMA Psychiatry 2018;75(6):623630. 10.1001/jamapsychiatry.2018.0544. [PubMed: 29710086]

9. Hwang CS, Kang EM, Kornegay CJ, et al. Trends in the concomitant prescribing of opioids and benzodiazepines, 2002-2014. Am J Prev Med 2016;51(2):151-160. 10.1016/j.amepre.2016.02.014. [PubMed: 27079639]

10. Jones CM, McAninch JK. Emergency department visits and overdose deaths from combined use of opioids and benzodiazepines. Am J Prev Med 2015;49(4):493-501. 10.1016/j.amepre. 2015.03.040. [PubMed: 26143953]

11. Vivolo-Kantor AM, Seth P, Gladden RM, et al. Vital signs: trends in emergency department visits for suspected opioid overdoses - United States, July 2016-September 2017. MMWR Morb Mortal Wkly Rep 2018;67(9):279-285. 10.15585/mmwr.mm6709e1. [PubMed: 29518069]

12. Jhung MA, Budnitz DS, Mendelsohn AB, et al. Evaluation and overview of the National Electronic Injury Surveillance System-Cooperative Adverse Drug Event Surveillance Project (NEISS-

CADES). Med Care 2007;45(10 suppl 2):S96-S102. 10.1097/MLR.0b013e318041f737. [PubMed: 17909391]

13. Schroeder T, Ault K. The NEISS sample (design and implementation) 1997 to present www.cpsc.gov//PageFiles/106617/2001d011-6b6.pdf. Updated June 1, 2001. Accessed March 28, 2018.

14. U.S. Consumer Product Safety Commission. NEISS - The National Electronic Injury Surveillance System: A Tool for Researchers www.cpsc.gov/PageFiles/106626/2000d015.pdf. Updated March 2000. Accessed October 1, 2018. 
15. HHS, CDC. Distinguishing public health research and public health nonresearch www.cdc.gov/od/ science/integrity/docs/cdc-policy-distinguishing-public-health-research-nonresearch.pdf. Published 2010. Updated July 31, 2018. Accessed December 16, 2018.

16. Saitz R Things that work, things that don't work, and things that matter-including words. J Addict Med 2015;9(6):429-430. 10.1097/ADM.0000000000000160. [PubMed: 26517322]

17. Wakeman SE. Language and addiction: choosing words wisely. Am J Public Health 2013;103(4):e1-e2. 10.2105/AJPH.2012.301191.

18. Piper BJ, Shah DT, Simoyan OM, et al. Trends in medical use of opioids in the U.S., 2006-2016. Am J Prev Med 2018;54(5):652-660. 10.1016/j.amepre.2018.01.034. [PubMed: 29551331]

19. Han B, Compton WM, Blanco C, et al. Prescription opioid use, misuse, and use disorders in U.S. adults: 2015 National Survey on Drug Use and Health. Ann Intern Med 2017;167(5):293-301. 10.7326/M17-0865. [PubMed: 28761945]

20. Coffin PO, Tracy M, Bucciarelli A, et al. Identifying injection drug users at risk of nonfatal overdose. Acad Emerg Med 2007;14(7):616-623. 10.1197/j.aem.2007.04.005. [PubMed: 17554010]

21. Larochelle MR, Liebschutz JM, Zhang F, et al. Opioid prescribing after nonfatal overdose and association with repeated overdose: a cohort study. Ann Intern Med 2016;164(1):1-9. 10.7326/ M15-0038. [PubMed: 26720742]

22. Olfson M, Crystal S, Wall M, et al. Causes of death after nonfatal opioid overdose. JAMA Psychiatry 2018;75(8):820-827. 10.1001/jamapsychiatry.2018.1471. [PubMed: 29926090]

23. Penm J, MacKinnon NJ, Lyons MS, et al. Combatting opioid overdoses in Ohio: emergency department physicians' prescribing patterns and perceptions of naloxone. J Gen Intern Med 2018;33(5):608-609. 10.1007/s11606-018-4353-6. [PubMed: 29492780]

24. HHS, Office of the Surgeon General. Surgeon General's Advisory on Naloxone and Opioid Overdose www.surgeongeneral.gov/priorities/opioid-overdose-prevention/naloxone-advisory.html. Updated April 2018. Accessed May 1, 2018.

25. Dowell D, Haegerich TM, Chou R. CDC guideline for prescribing opioids for chronic pain United States, 2016. MMWR Recomm Rep 2016;65(1):1-49. 10.15585/mmwr.rr6501e1.

26. Bohnert AS, Bonar EE, Cunningham R, et al. A pilot randomized clinical trial of an intervention to reduce overdose risk behaviors among emergency department patients at risk for prescription opioid overdose. Drug Alcohol Depend 2016;163:40-47. 10.1016/j.drugalcdep.2016.03.018. [PubMed: 27062245]

27. Coffin PO, Santos GM, Matheson T, et al. Behavioral intervention to reduce opioid overdose among high-risk persons with opioid use disorder: a pilot randomized controlled trial. PLoS One 2017;12(10):e0183354 10.1371/journal.pone.0183354. [PubMed: 29049282]

28. D’Onofrio G, Chawarski MC, O'Connor PG, et al. Emergency department-initiated buprenorphine for opioid dependence with continuation in primary care: outcomes during and after intervention. $\mathrm{J}$ Gen Intern Med 2017;32(6):660-666. 10.1007/s11606-017-3993-2. [PubMed: 28194688]

29. Larochelle MR, Bernson D, Land T, et al. Medication for opioid use disorder after nonfatal opioid overdose and association with mortality: a cohort study. Ann Intern Med 2018;169(3):137-145. 10.7326/M17-3107. [PubMed: 29913516]

30. Volkow ND, Wargo EM. Overdose prevention through medical treatment of opioid use disorders. Ann Intern Med 2018;169(3):190-192. 10.7326/M18-1397. [PubMed: 29913514]

31. HHS, Food and Drug Administration. FDA's Opioid Analgesic REMS Education Blueprint for Health Care Providers Involved in the Treatment and Monitoring of Patients with Pain (Revised FDA Blueprint) www.regulations.gov/contentStreamer?documentId=FDA-2017D-2497-0683\&attachmentNumber=1\&contentType=pdf. Updated January 2018. Accessed May 3, 2018.

32. HHS, Substance Abuse and Mental Health Services Administration and Health Resources and Services Administration. Drug \& Alcohol Use Screening Tools www.integration.samhsa.gov/ clinical-practice/screening-tools\#drugs. Updated 2018. Accessed May 11, 2018.

33. Soyka M Treatment of benzodiazepine dependence. N Engl J Med 2017;376(12):1147-1157. 10.1056/NEJMra1611832. [PubMed: 28328330] 
34. HHS, Substance Abuse and Mental Health Services Administration and Health Resources and Services Administration. Safe \& Effective Use of Benzodiazepines in Clinical Practice www.integration.samhsa.gov/about-us/Benzodiazepines_Presentation.pdf. Updated May 2017. Accessed May 16, 2018.

35. Schifano F Misuse and abuse of pregabalin and gabapentin: cause for concern? CNS Drugs 2014;28(6):491-496. 10.1007/s40263-014-0164-4. [PubMed: 24760436]

36. Evoy KE, Morrison MD, Saklad SR. Abuse and misuse of pregabalin and gabapentin. Drugs 2017;77(4):403-426. 10.1007/s40265-017-0700-x. [PubMed: 28144823]

37. Throckmorton DC, Gottlieb S, Woodcock J. The FDA and the next wave of drug abuse: proactive pharmacovigilance. N Engl J Med 2018;379(3):205-207. 10.1056/NEJMp1806486. [PubMed: 29847203]

38. Gottlieb S Emerging issues of misuse and abuse of OTC loperamide challenge FDA to address a new turn in the opioid addiction crisis, while maintaining access for patients https://blogs.fda.gov/ fdavoice/index.php/2018/05/emerging-issues-of-misuse-and-abuse-of-otc-loperamide-challengefda-to-address-a-new-turn-in-the-opioid-addiction-crisis-while-maintaining-access-for-patients/. Updated May 2018. Accessed May 13, 2018.

39. HHS, Food and Drug Administration. FDA Drug Safety Communication: FDA limits packaging for anti-diarrhea medicine loperamide (Imodium) to encourage safe use www.fda.gov/Drugs/ DrugSafety/ucm594232.htm. Updated January 2018. Accessed May 14, 2018.

40. King SA, Casavant MJ, Spiller HA, et al. Pediatric ADHD medication exposures reported to U.S. poison control centers. Pediatrics 2018;141(6):e20173872 10.1542/peds.2017-3872. [PubMed: 29784754]

41. Oquendo MA, Volkow ND. Suicide: a silent contributor to opioid-overdose deaths. N Engl J Med 2018;378(17):1567-1569. 10.1056/NEJMp1801417. [PubMed: 29694805]

42. Dunn KM, Saunders KW, Rutter CM, et al. Opioid prescriptions for chronic pain and overdose: a cohort study. Ann Intern Med 2010;152(2):85-92. 10.7326/0003-4819-152-2-201001190-00006. [PubMed: 20083827]

43. Fox KR, Millner AJ, Franklin JC. Classifying nonsuicidal overdoses: nonsuicidal self-injury, suicide attempts, or neither? Psychiatry Res 2016;244:235-242. 10.1016/j.psychres.2016.07.052. [PubMed: 27498057] 


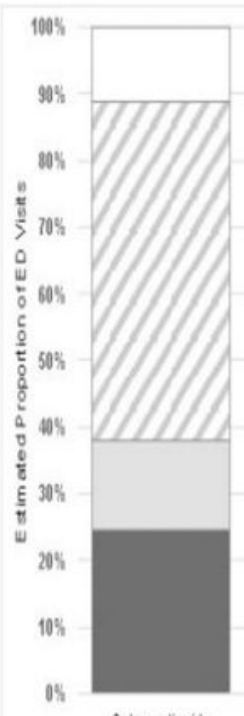

Gabserthoids

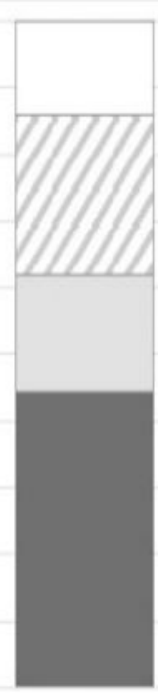

Benzodazepines

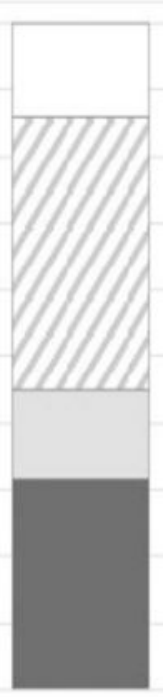

Hypotics (nonBentodiazepine)

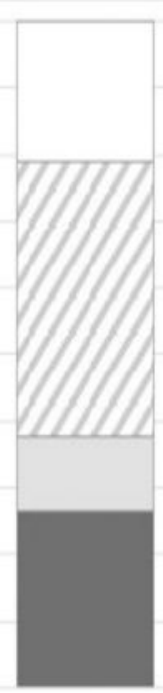

Muscle Relararts

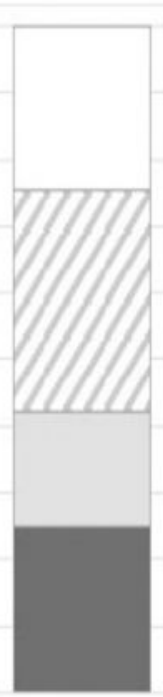

Antideresessants

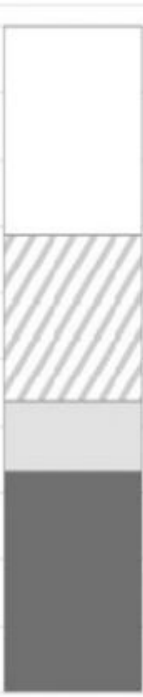

Prescifition Opioids

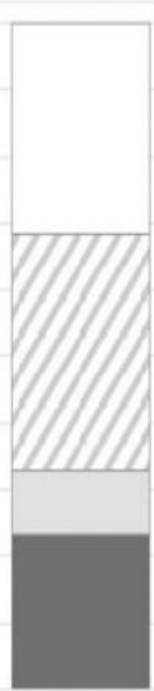

intossctotofes

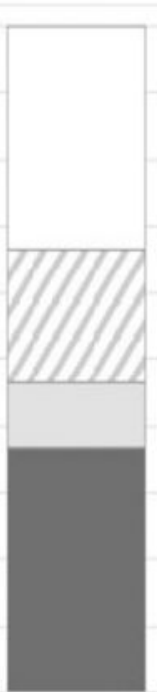

Stinulants

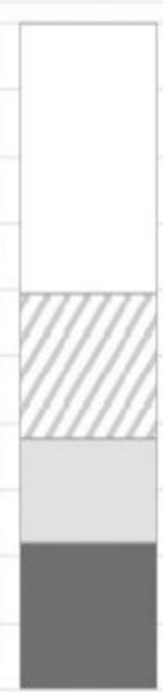

Coughicaldor Antristanine

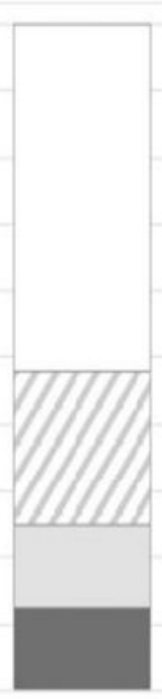

Nonocioid Analgesics IWith Illicit Drugs $\square$ With Alcohol a With Other Pharmaceutcals or Unspecified Drugs $\square$ Single Pharmaceutical Category Alone

Figure 1.

Substances involved in emergency department visits due to nonmedical use of pharmaceuticals, 2016. 


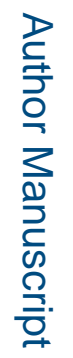

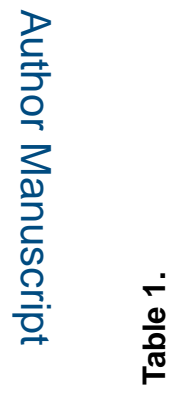

\begin{tabular}{|c|c|c|c|c|c|c|c|c|c|c|c|c|c|c|c|c|c|c|c|c|}
\hline 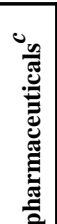 & 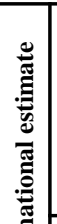 & $\begin{array}{l}\mathcal{O} \\
0 \\
0 \\
0 \\
0\end{array}$ & 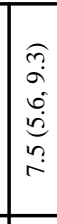 & 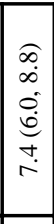 & 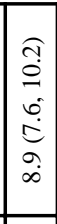 & $\left|\begin{array}{c}\hat{\sigma} \\
\alpha \\
\hat{\sigma} \\
\delta \\
\infty \\
\infty \\
\infty\end{array}\right|$ & 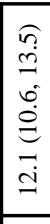 & 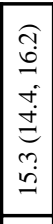 & 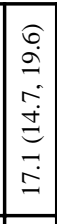 & 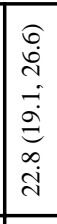 & 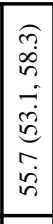 & 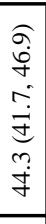 & 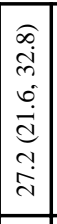 & $\begin{array}{l}f \\
\infty \\
0 \\
i \mathfrak{d} \\
\vec{b} \\
\infty \\
i \\
i\end{array}$ & 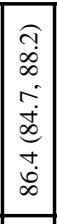 & $\mid \begin{array}{c}\hat{\widetilde{d}} \\
\mathrm{~d} \\
\overrightarrow{0} \\
\hat{0} \\
\hat{0}\end{array}$ & 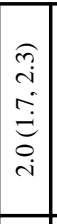 & 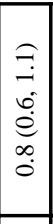 & 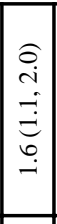 & 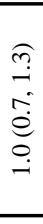 \\
\hline 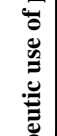 & 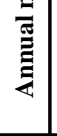 & $=$ & $\begin{array}{l}\text { ¿े } \\
\text { ò }\end{array}$ & $\begin{array}{l}\hat{a} \\
\dot{a} \\
\text { ò }\end{array}$ & $\mid \begin{array}{c}\infty \\
0 \\
0 \\
-\mathfrak{m} \\
-\end{array}$ & $\begin{array}{l}\infty \\
\infty \\
\circ \\
\stackrel{2}{2} \\
\end{array}$ & 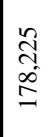 & 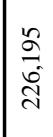 & 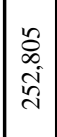 & 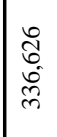 & 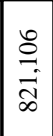 & 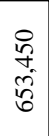 & $\begin{array}{l}\overrightarrow{\tilde{g}} \\
\overrightarrow{\vec{q}}\end{array}$ & 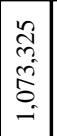 & 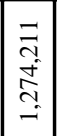 & $\begin{array}{l}2 \\
0 \\
0 \\
0 \\
0\end{array}$ & $\begin{array}{l}\infty \\
\widetilde{i} \\
\tilde{\lambda}\end{array}$ & $\begin{array}{l}\bar{g} \\
\mathbf{a}\end{array}$ & 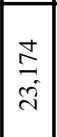 & \begin{tabular}{l} 
o \\
\multirow{2}{n}{} \\
\end{tabular} \\
\hline 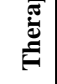 & $\begin{array}{l}\text { שै } \\
\text { שै }\end{array}$ & $=$ & $\begin{array}{l}\text { 点 } \\
\text { î }\end{array}$ & 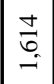 & $\begin{array}{l}0 \\
0 \\
-2\end{array}$ & 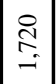 & $\mid \begin{array}{c}8 \\
i n \\
i\end{array}$ & $\stackrel{\partial}{\Rightarrow}$ & 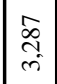 & \begin{tabular}{|l}
$\infty$ \\
$\stackrel{\infty}{+}$ \\
\multirow{f}{*}{}
\end{tabular} & $\stackrel{\substack{n \\
=}}{ }$ & $\begin{array}{l}\text { ơ } \\
\vdots \\
a\end{array}$ & $\left|\begin{array}{c}0 \\
⿱ \\
\vdots \\
0 \\
6\end{array}\right|$ & $\begin{array}{l}\hat{2} \\
\stackrel{2}{ \pm}\end{array}$ & $\begin{array}{l}\infty \\
\stackrel{0}{0} \\
\infty\end{array}$ & $\begin{array}{l}0 \\
\infty \\
0 \\
i\end{array} \mid$ & के & 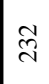 & 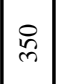 & $\ddot{n}$ \\
\hline
\end{tabular}

로을

\begin{tabular}{|c|c|c|c|c|c|c|c|c|c|c|c|c|c|c|c|c|c|c|c|c|c|c|c|c|c|}
\hline 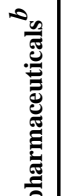 & 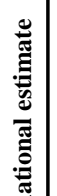 & $\begin{array}{l}0 \\
0 \\
8 \\
0 \\
0 \\
0^{\circ}\end{array}$ & & 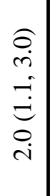 & 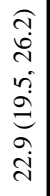 & 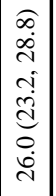 & 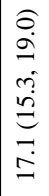 & 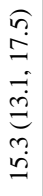 & 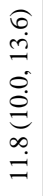 & \begin{tabular}{|c|}
$\hat{\sigma}$ \\
$\dot{+}$ \\
$\dot{d}$ \\
$\dot{d}$ \\
$\infty$ \\
$\dot{r}$
\end{tabular} & 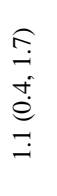 & & 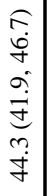 & 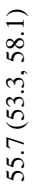 & & 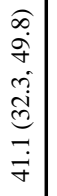 & 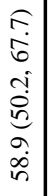 & & $\begin{array}{l}a \\
\dot{a} \\
i \\
\vec{d} \\
\vec{d} \\
\vec{i} \\
\vec{i}\end{array}$ & 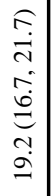 & 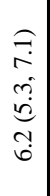 & 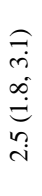 & & 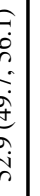 & $\mid \begin{array}{c}\sigma \\
\tilde{\lambda} \\
\alpha \\
\alpha \\
\dot{\partial} \\
\infty \\
\dot{\lambda} \\
\dot{\lambda}\end{array}$ \\
\hline 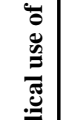 & 㯊 & $=$ & & $\stackrel{m}{\stackrel{m}{\rightleftharpoons}}$ & $\begin{array}{l}\infty \\
\stackrel{1}{1} \\
\vec{\infty}\end{array}$ & $\begin{array}{c}\hat{\Xi} \\
\text { } \\
\end{array}$ & $\begin{array}{l}\stackrel{5}{f} \\
\vec{b}\end{array}$ & 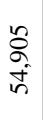 & $\begin{array}{l}\vec{b} \\
\vec{j} \\
\vec{f}\end{array}$ & $\mid \begin{array}{c}n \\
q \\
q \\
c \\
-1\end{array}$ & 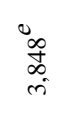 & & 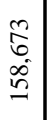 & $\begin{array}{l}\frac{\pi}{n} \\
\text { a } \\
2\end{array}$ & & $\begin{array}{l}\vec{a} \\
\dot{\Xi} \\
\dot{ \pm}\end{array}$ & $\begin{array}{l}\stackrel{0}{\circ} \\
\stackrel{\vec{n}}{\vec{n}}\end{array}$ & & 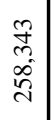 & 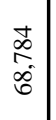 & $\begin{array}{l}\frac{n}{N} \\
\text { ì }\end{array}$ & 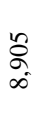 & & $\begin{array}{l}6 \\
0 \\
0 \\
0 \\
0 \\
0\end{array}$ & $\mid \begin{array}{l}\hat{N} \\
\infty \\
\infty\end{array}$ \\
\hline 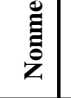 & 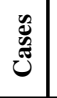 & $=$ & & ถิ) & 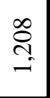 & 总 & $\tilde{\infty}$ & $\stackrel{2}{\curvearrowright}$ & $\stackrel{\substack{\infty \\
i n}}{i n}$ & $\stackrel{\infty}{\stackrel{\infty}{\infty}}$ & $q$ & & $\begin{array}{l}\stackrel{a}{\vec{v}} \\
\vec{i}\end{array}$ & ભે & & $\begin{array}{l}0 \\
0 \\
0 \\
i\end{array}$ & iq & & $\begin{array}{l}\stackrel{a}{:} \\
\stackrel{r}{0}\end{array}$ & $\begin{array}{c}\tilde{\delta} \\
-=\end{array}$ & 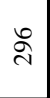 & $\cong$ & & 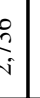 & $\stackrel{g}{g}$ \\
\hline 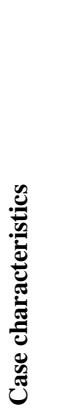 & & & 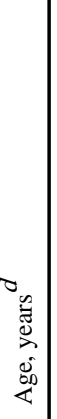 & $\frac{n}{v}$ & \begin{tabular}{l}
\multirow{1}{N}{} \\
$i$
\end{tabular} & 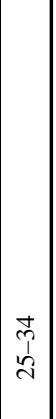 & $\begin{array}{l}\underset{+}{7} \\
\text { 心 }\end{array}$ & 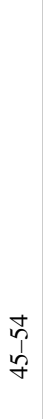 & $\begin{array}{l}\text { to } \\
\text { in } \\
\text { in }\end{array}$ & $\begin{array}{l}+5 \\
1 \\
6\end{array}$ & $\underset{\lambda}{+}$ & 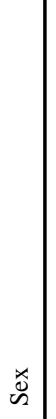 & 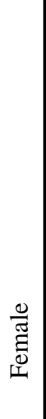 & $\frac{0}{\frac{0}{\pi}}$ & 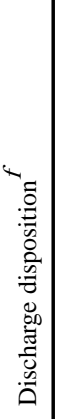 & 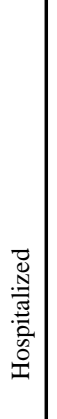 & 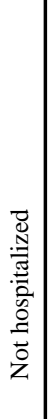 & 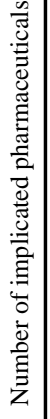 & - & 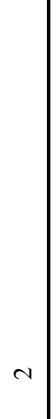 & $m$ & $\begin{array}{l}\stackrel{0}{0} \\
\stackrel{0}{\Xi} \\
\vdots \\
+\end{array}$ & 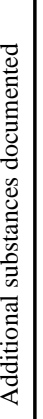 & 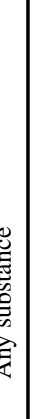 & $\begin{array}{l} \\
\overline{0} \\
\frac{0}{0} \\
\frac{0}{4}\end{array}$ \\
\hline
\end{tabular}

Am J Prev Med. Author manuscript; available in PMC 2020 May 01. 


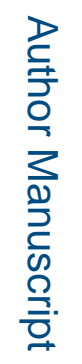

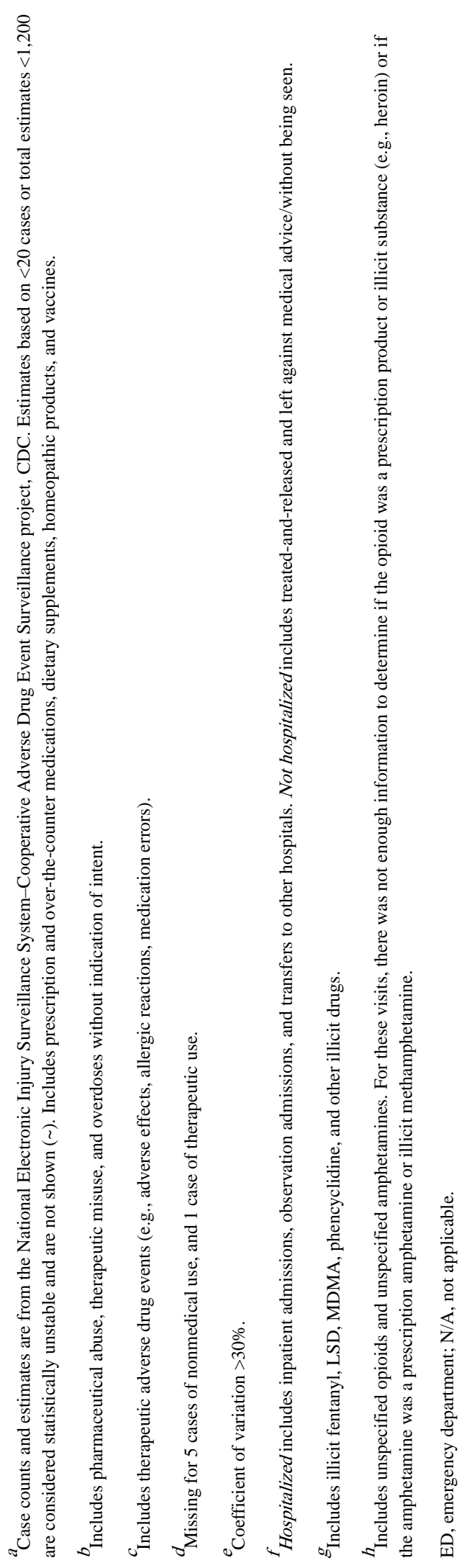

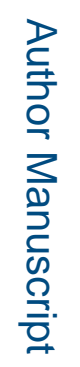
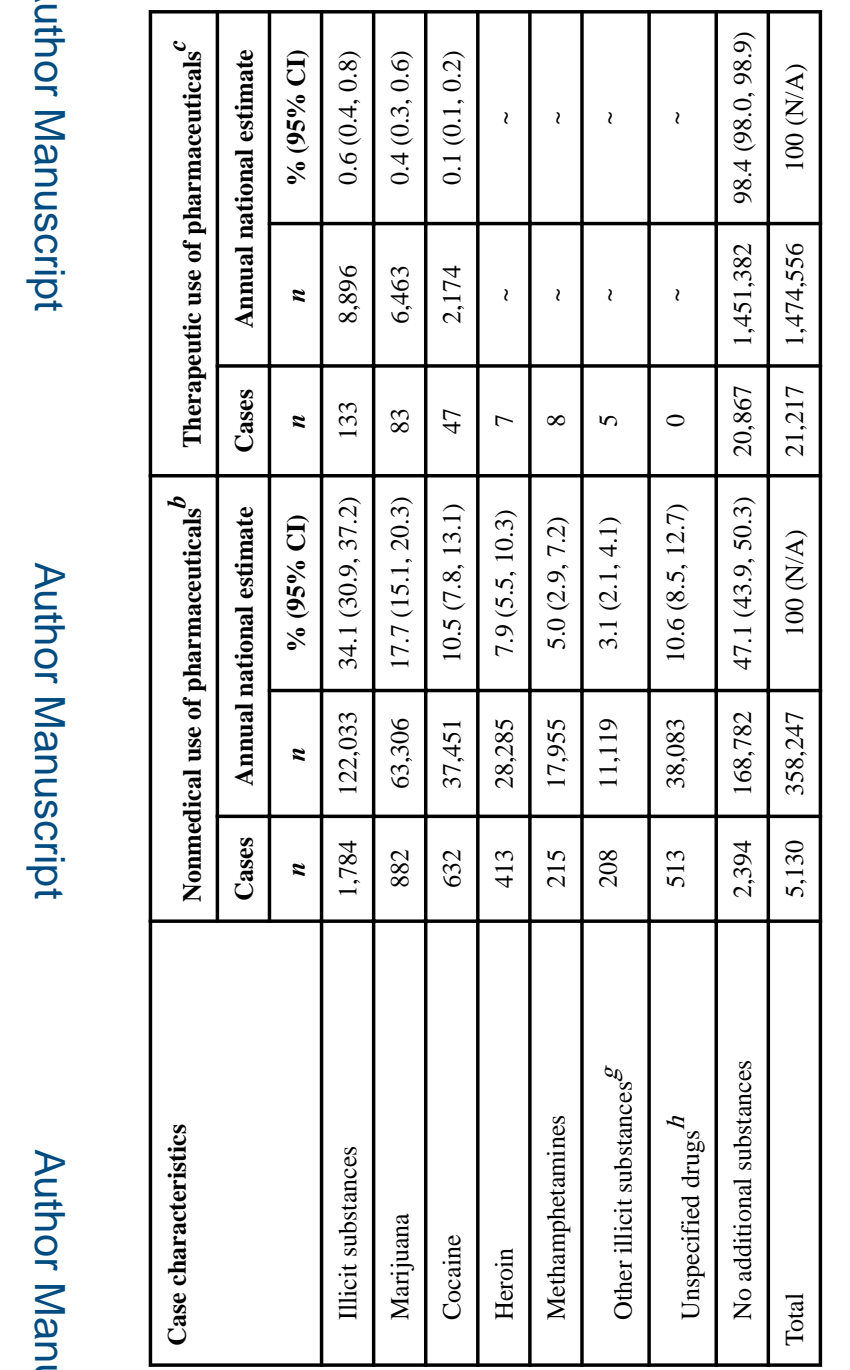

Am J Prev Med. Author manuscript; available in PMC 2020 May 01. 


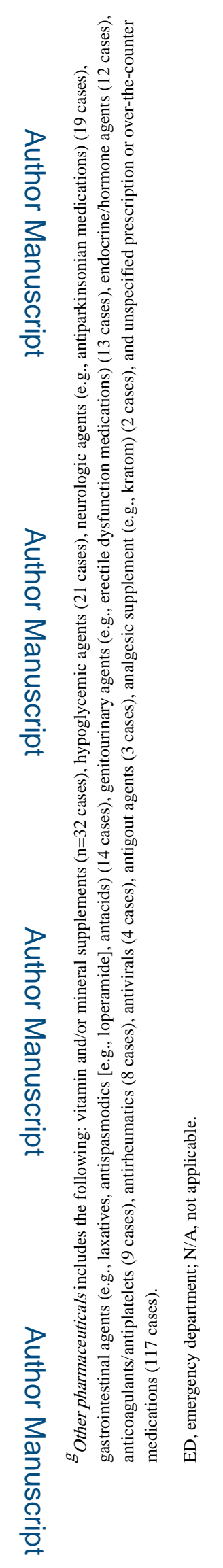

Am J Prev Med. Author manuscript; available in PMC 2020 May 01. 


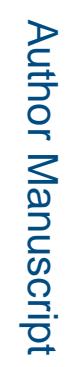

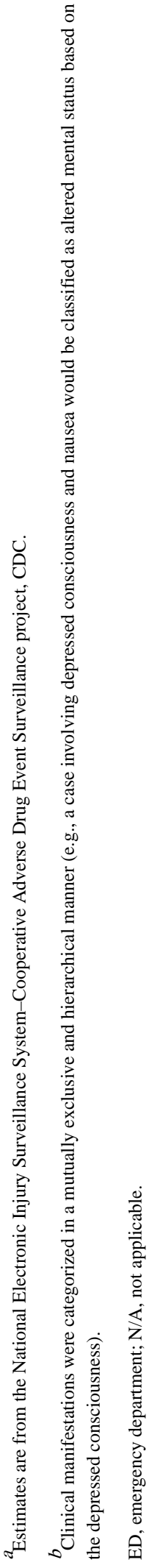

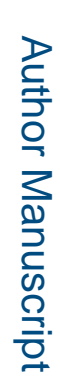

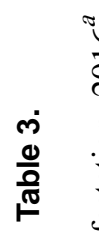

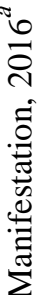

苞

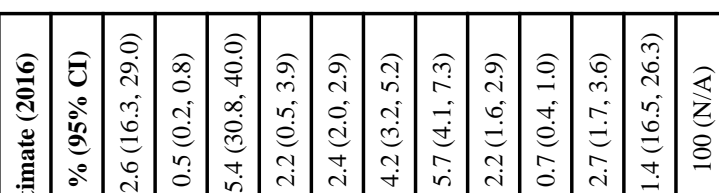

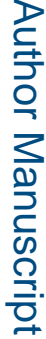

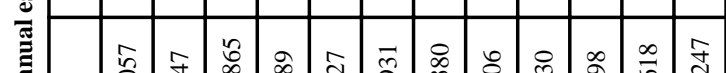

焉

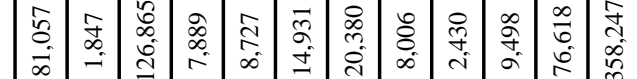

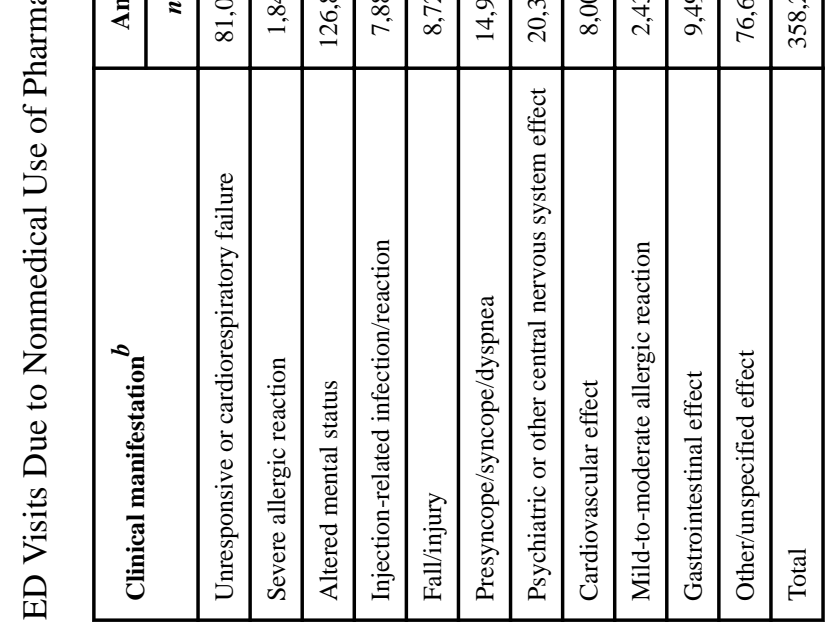

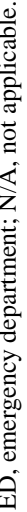

Am J Prev Med. Author manuscript; available in PMC 2020 May 01. 